\title{
Produtividade e exportação de nutrientes em feijão-vagem adubado com esterco de galinha
}

\author{
Ivan de Paiva Barbosa Magalhães ${ }^{1 *}$, Maria Aparecida Nogueira Sediyama², Fred Denilson Barbosa da Silva ${ }^{3}$, \\ Sanzio Mollica Vidigal ${ }^{4}$, Cláudia Lúcia Oliveira Pinto ${ }^{4}$, Iza Paula Carvalho Lopes ${ }^{3}$
}

$10.1590 / 0034-737 X 201764010014$

\begin{abstract}
RESUMO
A análise do acúmulo e da exportação de nutrientes pela cultura de feijão-vagem é fundamental para programa de adubação mais sustentável, pois a definição das doses de adubos orgânicos com base apenas na produção máxima estimada não garante a manutenção da fertilidade do solo. Objetivou-se, com este trabralho, avaliar o efeito da adubação com esterco de galinha sobre a produtividade, o acúmulo e a exportação de nutrientes pelas vagens de feijão-vagem.

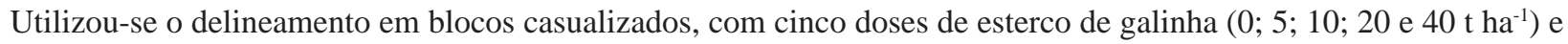
quatro repetições. Foram constatados maiores teores de $\mathrm{Pe} \mathrm{Mg}$ nas folhas com aplicação da dose de $40 \mathrm{t} \mathrm{ha}^{-1}$ de esterco. O comprimento máximo da vagem foi $14,47 \mathrm{~cm}$, estimado com a dose de $33,33 \mathrm{tha}^{-1}$ de esterco. Os maiores valores de diâmetro, número de vagens por planta e produtividade de vagens foram observados na maior dose de esterco aplicada. Em termos relativos, ou seja, total exportado em relação ao total extraído pela parte aérea, o fósforo é o nutriente mais exportado pelas vagens, em média de 58\%, seguidos pelo $\mathrm{N}(55 \%), \mathrm{K}(43 \%), \mathrm{Mg}(40 \%), \mathrm{S}(38 \%)$ e pelo Ca (17\%). Na maior dose, embora o acúmulo de Ca tenha ocorrido em grande quantidade ( $\left.31,3 \mathrm{~kg} \mathrm{ha}^{-1}\right)$, apenas $13 \%$ dele foram exportados pelas vagens. A adubação do feijão-vagem com esterco de galinha supre os nutrientes essenciais e aumenta a produtividade de vagens, de 7,2 (sem adubação), para 16,3 t ha' (adubação com $40 \mathrm{t} \mathrm{ha}^{-1}$ de esterco de galinha). Os restos vegetais do feijão-vagem constituem importante fonte de nutrientes, sendo obtidas na maior dose de esterco aplicada $\left(40 \mathrm{tha}^{-1}\right)$ as seguintes quantidades de macronutrientes $\left(\mathrm{kg} \mathrm{ha}^{-1}\right)$ : $\mathrm{N}(51,4) ; \mathrm{P}(5,1) ; \mathrm{K}(27,6) ; \mathrm{Ca}(27,1) ; \mathrm{Mg}(8,2) ; \mathrm{S}(5,1)$, que poderão retornar ao solo, com a incorporação das plantas.
\end{abstract}

Palavras-chave: Phaseolus vulgaris; conteúdo de nutrientes; cultivo orgânico; nutrição de plantas.

\section{ABSTRACT}

\section{Yield and export of nutrients in chicken manure-fertilized snap bean}

The analysis of nutrient accumulation and exportation in snap bean is fundamental to help develop a more sustainable fertilization, since defining the organic fertilizer doses needed for snap bean cultivation based only on an estimated maximum production does not guarantee that soil fertility is maintained. The objective of this study was to evaluate the effect of chicken manure fertilizer on snap bean yield, accumulation, and nutrient exportation. The experiment was arranged in a randomized block design, with five chicken manure fertilizer doses $\left(0 ; 5 ; 10 ; 20\right.$, and $\left.40 \mathrm{tha}^{-1}\right)$ and four repetitions. Higher $\mathrm{P}$ and $\mathrm{Mg}$ contents were verified in the leaves following application of chicken manure fertilizer dose of $40 \mathrm{tha}^{-1}$. Maximum pod length was $14.47 \mathrm{~cm}$, estimated with chicken manure fertilizer dose of $33.33 \mathrm{tha}^{-1}$. The highest diameter, number of pods per plant, and pod yield were verified at the highest chicken manure fertilizer dose

\footnotetext{
Submetido em 11/06/2015 e aprovado em 17/10/2016.

1 Universidade Federal de Viçosa, Viçosa, Minas Gerais, Brasil. Bolsista PIBIC FAPEMIG/EPAMIG. ivan.barbosa@ufv.br

${ }^{2}$ Pesquisadora/Bolsista CNPq/EPAMIG. Viçosa, Minas Gerais, Brasil. marians@epamig.br

${ }^{3}$ Bolsista FAPEMIG/EPAMIG. Viçosa, Minas Gerais, Brasil. izzaagro@yahoo.com.br; freddenilson@gmail.com

${ }^{4}$ Pesquisador/Bolsista BIPDT FAPEMIG/EPAMIG. Viçosa, Minas Gerais, Brasil. sanziomv@ gmail.com clucia@epamig.ufv.br

*Autor para correspondência: ivan.barbosa@ufv.br
}

Rev. Ceres, Viçosa, v. 64, n.1, p. 098-107, jan/fev, 2017 
applied $\left(40 \mathrm{t} \mathrm{ha}^{-1}\right)$. In relative terms, i.e., total exported in relation to total extracted of the aerial part, phosphorus is the most exported nutrient in the pods, at an average of 58\%, followed by $\mathrm{N}(55 \%), \mathrm{K}(43 \%), \mathrm{Mg}(40 \%), \mathrm{S}(38 \%)$, and Ca $(17 \%)$. Although a large amount of Ca accumulation $\left(31.3 \mathrm{~kg} \mathrm{ha}^{-1}\right)$ was verified at the highest dose, only $13 \%$ of it was exported by the pods. Chicken manure fertilizer supplies the essential nutrients and increases pod yield from 7.2 to 16.3 $\mathrm{t} \mathrm{ha}^{-1}$, when comparing between no fertilization and the highest chicken manure fertilizer dose. The cultural residues of snap beans are an important source of $\mathrm{Ca}$ and $\mathrm{Mg}$, with the following nutrient amounts $\left(\mathrm{kg} \mathrm{ha}^{-1}\right)$ : $\mathrm{N}(51.4) ; \mathrm{P}(5.1)$; K (27.6); $\mathrm{Ca}$ (27.1); $\mathrm{Mg}$ (8.2); and S (5.1) obtained at the highest chicken manure fertilizer dose applied (40 $\left.\mathrm{tha}^{-1}\right)$, which can return to soil through incorporation by the plants.

Key words: Phaseolus vulgaris; nutrient content; organic cultivation; plant nutrition.

\section{INTRODUÇÃO}

O feijão-vagem (Phaseolus vulgaris L.) está entre as hortaliças mais consumidas no Brasil, com produção de $56.776 \mathrm{t}$ de vagens (IBGE, 2006). Nesse último censo agropecuário, Minas Gerais apresentou-se com 27,8\% da produção nacional, com 15.501 t de vagens. Parte da produção do Estado é comercializada nas Unidades Centrais de Revenda e Abastecimento, com a movimentação média mensal de $712 \mathrm{t}$ de vagens (CEASAMINAS, 2013).

A produção de feijão-vagem é realizada, principalmente, em pequenas propriedades rurais (Peixoto et al., 2002). No entanto, o parco desenvolvimento de tecnologias direcionadas para o cultivo orgânico dessa hortaliça limita a obtenção de produções sustentáveis. Uma das estratégias que se destaca no cultivo orgânico é o aproveitamento de resíduos orgânicos na adubação, usados especialmente por agricultores familiares, por sua adequação às características das pequenas propriedades (Sediyama et al., 2014).

Minas Gerais está entre os principais Estados produtores de aves, atividade que gera grande volume de resíduos orgânicos, em especial as camas de galinhas poedeiras e de frangos de corte (UBA, 2014). Em geral, esses adubos orgânicos são muito utilizados na produção de hortaliças, por seus teores de nutrientes, especialmente nitrogênio, cálcio e fósforo, mais altos que os do esterco bovino, do húmus de minhoca e dos compostos orgânicos (Abreu et al., 2010).

A cultura do feijão-vagem é conhecida por ser responsiva ao fósforo, com aumento significativo de vagens por planta e, consequentemente, maior produtividade (Oliveira et al., 2005). Essa característica, juntamente com o baixo teor de fósforo e sua alta adsorção nos solos de Minas Gerais, exige que a adubação seja realizada constantemente (Santos et al., 2008). Além disso, o feijoeiro é cultura exigente em nutrientes, em função do pequeno e pouco profundo sistema radicular e do ciclo curto. A absorção de nutrientes, especialmente o N, ocorre pratica- mente durante todo o ciclo da cultura, mas a época de maior exigência, quando a velocidade de absorção é máxima, ocorre dos 35 aos 50 dias da emergência da planta, coincidindo com a época do florescimento. Neste período, o feijoeiro absorve de 2,0 a 2,5 kg N/ha dia (Rosolem \& Marubayashi, 1994).

Outro fator importante que afeta a produtividade de vagens é que as quantidades de $\mathrm{N}$ absorvidas pelo feijoeiro, oriundas da mineralização da matéria orgânica do solo e da simbiose com as bactérias do gênero Rhizobium, não são suficientes para se alcançarem altas produtividades (Brito et al., 2011; Souza et al., 2011; Perez et al., 2013). A aplicação de adubo orgânico a partir da produtividade esperada é uma estratégia utilizada no cultivo do feijão-vagem para suprir adequadamente a demanda de $\mathrm{N}$ da cultura.

Alguns trabalhos sugerem que a aplicação de cama de frango eleva o rendimento do cultivo de feijão-vagem. Santos et al. (2001) aplicaram esterco de galinha na dose de 13 t ha ${ }^{-1}$ e obtiveram a produtividade máxima de $26,3 \mathrm{tha}^{-1} \mathrm{de}$ vagens com o cultivar Macarrão Favorito, tipo trepador. Em outro trabalho, a aplicação de $26 \mathrm{t} \mathrm{ha}^{-1}$ de cama de aviário com $16,3 \%$ de umidade proporcionou produtividade máxima de $20 \mathrm{t} \mathrm{ha}^{-1}$ de vagens, com o cv. Alessa (Oliveira et al., 2006). Apesar do aumento da produtividade de vagens, outras informações técnicas são necessárias para melhorar o manejo com os adubos orgânicos.

Quantificar a extração e a exportação de nutrientes no cultivo de feijão-vagem pode fornecer dados importantes para a definição das doses de cama de frango mais sustentáveis, ou seja, que utilizem o mínimo de adubo, sem reduzir o potencial de ganho na produtividade. Embora essas informações sejam importantes para o programa de adubação e manejo do resíduo, há carência de estudos para o cultivo dessa hortaliça, tanto com adubação química, quanto com orgânica.

No cultivo de Phaseolus vulgaris para produção de grãos, a aplicação de $120 \mathrm{~kg} \mathrm{ha}^{-1}$ de $\mathrm{N}$ proporcionou a extração de 84,2 e $40 \mathrm{~kg} \mathrm{ha}^{-1}$ e exportação de 80,2 e $55 \mathrm{~kg}^{\mathrm{h}}$ ha- 
${ }^{1}$ de N, no sistema de plantio direto, nos anos agrícolas 2007/08 e 2008/09, respectivamente (Perez et al., 2013). É provável que o cultivo de feijoeiro, em relação à extração e à exportação de nutrientes, apresente comportamentos diferentes, quanto aos objetivos de comercializar grãos ou vagens. Assim, objetivou-se, neste trabalho, avaliar o efeito da adubação orgânica com esterco de galinha sobre o estado nutricional, o acúmulo e a exportação de nutrientes e a produtividade de feijão-vagem, cv. Macarrão Favorito, tipo trepador.

\section{MATERIAL E MÉTODOS}

O experimento foi conduzido no Campo Experimental da Empresa de Pesquisa Agropecuária de Minas Gerais EPAMIG, em Oratórios, MG, de 23/04 a 03/07/2012. Aárea experimental está situada em $20^{\circ} 25^{\prime} 49^{\prime \prime} \mathrm{S}$ e $42^{\circ} 48^{\prime} 20^{\prime \prime} \mathrm{O}$, em altitude média de $500 \mathrm{~m}$. O clima da região varia do tipo Cwa, tropical úmido, a Aw, semiúmido de verões quentes; a vegetação natural é de floresta tropical semidecidual ou ombrófila mista (Cunha et al., 2000). A precipitação média anual é de $1.250 \mathrm{~mm}$, a temperatura máxima média anual de $21,8^{\circ} \mathrm{C}$ e, a mínima média anual, de $19,5^{\circ} \mathrm{C}$.

O solo, Argissolo Vermelho-Amarelo câmbico, fase terraço, apresentou na camada de $0-20 \mathrm{~cm}: \mathrm{pH}\left(\mathrm{H}_{2} \mathrm{O}\right)=6,0 ; \mathrm{P}=$ $13,4 \mathrm{mg} / \mathrm{dm}^{3} ; \mathrm{K}=142 \mathrm{mg} / \mathrm{dm}^{3} ; \mathrm{Ca}^{+2}=2,0 \mathrm{cmol} / \mathrm{dm}^{3} ; \mathrm{Mg}^{+2}=$ $1,0 \mathrm{cmol} / \mathrm{dm}^{3} ; \mathrm{Al}^{+3}=0,0 ; \mathrm{V}=58 \%$ e matéria orgânica $=2,1$ dag/kg (Embrapa, 2013).

Utilizou-se o delineamento experimental em blocos casualizados, com cinco tratamentos e quatro repetições. Os tratamentos foram constituídos pelas doses do esterco de galinha curtido: $0,5,10,20$ e $40 \mathrm{t} \mathrm{ha}^{-1}$.

O esterco de galinha foi armazendo por seis meses e na época da sua aplicação apresentou as seguintes características (g/kg): $\mathrm{N}=24,1 ; \mathrm{P}=21,6 ; \mathrm{K}=1,0 ; \mathrm{Ca}=115,4 ; \mathrm{Mg}=6,7 \mathrm{e}$ $\mathrm{S}=4,0 ;$ para C.O.=19,97 dag/kg, $\mathrm{pH}=8,20, \mathrm{C} / \mathrm{N}=8,28$ e teor de umidade $=13,44 \%$, em estufa a $75^{\circ} \mathrm{C}$. A aplicação de plantio, de metade da dose definida para cada tratamento, foi realizada na profundidade de $0-15 \mathrm{~cm}$ e incorporada com enxada, uma semana antes da semeadura (18/04/2012). O restante foi aplicado em cobertura e incorporado à profundidade $0-5$ cm, aos 30 dias após a semeadura (23/05/2012).

Cada parcela continha 40 plantas, em quatro fileiras de 3,0 m de comprimento, espaçadas de 1,0 m. O espaçamento entre plantas foi de $0,3 \mathrm{~m}$. Foram colhidas 16 plantas centrais, em cada parcela. A semeadura foi realizada com as sementes de feijão-vagem do cultivar Macarrão Favorito, tipo trepador. Foram semeadas duas sementes por cova e aos 15 dias após a semeadura foi realizado o desbaste, deixando-se uma planta por cova.

O manejo de plantas daninhas foi realizado por meio de duas capinas com enxadas, nas linhas, e três roçadas na parte externa das linhas de plantio. As irrigações foram feitas pelo método de gotejamento, usando-se fitas perfuradas com intervalos de $10 \mathrm{~cm}$, dispostas em cada fileira de plantas. Foram feitas pulverizações quinzenais com urina de vaca fermentada a $1,0 \%$, até o florescimento das plantas. A análise química da urina indicou as seguintes características, em \%: $\mathrm{N}=6,96 ; \mathrm{P}=0,0 ; \mathrm{K}=0,89 ; \mathrm{Ca}=0,00 ; \mathrm{Mg}=0,04$; $\mathrm{S}=0,03 ; \mathrm{C}$. Org. $=0,17 ; \mathrm{em} \mathrm{mg} / \mathrm{kg} \mathrm{Zn}=0,0 ; \mathrm{Fe}=1,0 ; \mathrm{Mn}=0,0$; $\mathrm{Cu}=0,0$ e $\mathrm{pH}=8,5$.

Quando as plantas estavam em pleno florescimento, aos 40 dias de idade, realizou-se a coleta da quarta folha, indicadora do estado nutricional, em seis plantas de cada parcela. O material foi secado em estufa com circulação de ar, à temperatura de $65^{\circ} \mathrm{C}$, por $72 \mathrm{~h}$, foi moído e amostras foram enviadas para determinação dos teores de N, P, K, $\mathrm{Ca}, \mathrm{Mg}$ e S, de acordo com procedimento da Embrapa (2009).

A colheita foi iniciada aos 58 dias após a semeadura, quando as vagens estavam tenras. Quatro coletas por semana foram realizadas durante 22 dias, para evitar vagens com características fora do ponto ideal de colheita. No momento da coleta, as vagens foram separadas em comerciais e não comerciais, em cada parcela.

As vagens comercializáveis coletadas foram pesadas, contadas e medidas em cada colheita. A pesagem e a contagem das vagens foram realizadas imediatamente após a classificação, para quantificar a massa da matéria fresca e o número de vagens, respectivamente. $\mathrm{O}$ diâmetro foi medido na posição central e, o comprimento, entre as extremidades da vagem. Ao final das colheitas, somaram-se os valores obtidos em cada coleta e dividiu-se o valor total pelo número de plantas correspondente à área útil de cada parcela. Os resultados foram expressos em gramas por planta, para massa de vagens frescas; número de vagens por planta; comprimento $(\mathrm{cm})$ e diâmetro $(\mathrm{mm})$ de vagens.

Para determinação da umidade foi retirada uma amostra de 20 vagens, ao acaso, de cada parcela. As vagens foram submetidas à secagem em estufa de circulação forçada de ar, com temperatura de $65^{\circ} \mathrm{C}$, por $72 \mathrm{~h}$. Pesou-se e calculou-se a umidade das vagens para, finalmente, calcular a massa das vagens secas.

A produtividade foi obtida a partir do valor total da massa de vagens frescas de cada parcela, obtida ao longo das colheitas realizadas. O resultado foi expresso em toneladas de vagens por hectare.

Após a última coleta das vagens (80 dias), as folhas, ramos e os caules das plantas foram coletados, pesados e picados separadamente. Em seguida, coletou-se uma amostra deste material picado para secagem em estufa com circulação de ar, à temperatura de $65^{\circ} \mathrm{C}$, por $72 \mathrm{~h}$. Após essa secagem, o material foi moído e as amostras foram enviadas ao laboratório, para determinar os teores de N, P, K, $\mathrm{Ca}, \mathrm{Mg}$ e $\mathrm{S}$, de acordo com procedimento da Embrapa (2009). 
O acúmulo de nutrientes foi calculado a partir do teor do nutriente das folhas, dos ramos e das vagens e convertido para $\mathrm{kg} \mathrm{ha}^{-1}$, de acordo com a massa da matéria seca de cada componente. A exportação de nutrientes foi determinada a partir do teor de nutrientes nas vagens e convertida em $\mathrm{kg} \mathrm{ha}^{-1}$, de acordo com a média da massa de matéria seca das vagens, obtida ao longo das coletas realizadas no experimento.

Os dados foram analisados, utilizando-se o programa estatístico SAEG (SAEG, 2007), sendo submetidos à análise de variância e de regressão polinomial, a 5\% de probabilidade. Os modelos foram escolhidos com base no significado biológico, maior significância dos regressores e coeficiente de determinação.

\section{RESULTADOS E DISCUSSÃO}

$\mathrm{Na}$ avaliação do estado nutricional das plantas, as doses de esterco de galinha influenciaram positivamente nos teores foliares de fósforo e magnésio, mas não apresentaram efeito significativo sobre os teores de $\mathrm{N}, \mathrm{K}, \mathrm{Ca}$ e $\mathrm{S}$, cujos valores médios foram: 44,7, 17,5, 10,2 e 2,2 $\mathrm{g} \mathrm{kg}^{-1}$, respectivamente. À exceção do $\mathrm{K}$ e do $\mathrm{Ca}$, os teores de nutrientes apresentaram-se dentro do intervalo considerado adequado para a cultura: $\mathrm{N}\left(40-60 \mathrm{~g} \mathrm{~kg}^{-1}\right), \mathrm{P}(3-7 \mathrm{~g} \mathrm{~kg}$ $\left.{ }^{1}\right), \mathrm{Mg}\left(3-8 \mathrm{~g} \mathrm{~kg}^{-1}\right)$ e S (2-5 $\left.\mathrm{g} \mathrm{kg}^{-1}\right)$, de acordo com Raij et al. (1997).

Os teores médios de $\mathrm{K}$ e de $\mathrm{Ca}$ encontrados nas folhas foram inferiores aos valores de referência: 25-40 g $\mathrm{kg}^{-1}$ de K e 15-30 $\mathrm{g} \mathrm{kg}^{-1}$ de Ca (Raij et al. 1997). O baixo teor foliar de $\mathrm{K}$ deve-se, provavelmente, ao baixo teor desse nutriente no esterco de galinha (1,0 $\left.\mathrm{g} \mathrm{kg}^{-1} \mathrm{de} \mathrm{K}\right)$, além da maior quantidade de $\mathrm{Ca}$ aplicada com o esterco $\left(115,4 \mathrm{~g} \mathrm{~kg}^{-1} \mathrm{de} \mathrm{Ca}\right)$, que pode ter levado a uma inibição da absorção de $\mathrm{K}$, por competição, pelo excesso de $\mathrm{Ca}$, como observado para algumas plantas (Malavolta et al., 1997). Por outro lado, o esterco apresentou alto teor de $\mathrm{Ca}\left(115,4 \mathrm{~g} \mathrm{~kg}^{-1}\right)$, mas não foi suficiente para proporcio- nar aumento do teor nas folhas indicadoras. É provável que o fornecimento de $\mathrm{Ca}$ pelo esterco de galinha, por sua baixa translocação na planta, não tenha favorecido maior absorção desse nutriente (Brackmann et al., 2010). No entanto, o baixo teor de cálcio nas folhas não refletiu em queda da produtividade; além disso, a planta não expressou características morfológicas que mostrassem deficiência desse elemento. Miranda et al. (2010), em estudo da resposta de feijão-de-corda decorrente da omissão de macro e micronutrientes, observaram que o Ca é o primeiro nutriente cuja deficiência manifesta-se em sintomas visíveis, além de sua ausência ser fator responsável pelo maior prejuízo ao desenvolvimento e à produção da biomassa das plantas.

A aplicação de esterco de galinha proporcionou aumento do teor de fósforo e de magnésio na folha indicadora. $\mathrm{O}$ teor foliar de $\mathrm{P}$ respondeu de forma quadrática, e o de $\mathrm{Mg}$ de forma linear, às doses de esterco. Os maiores teores foliares, 5,53 $\mathrm{g} \mathrm{kg}^{-1}$ de $\mathrm{P}$ e 4,4 $\mathrm{g} \mathrm{kg}^{-1} \mathrm{de} \mathrm{Mg}$, foram obtidos na maior dose de esterco aplicada (Figuras 1A e 1B). O fornecimento equilibrado de fósforo, desde o início do desenvolvimento vegetativo, estimula o crescimento radicular logo na fase inicial e melhora a formação dos primórdios das partes reprodutivas e dos frutos (Raij, 1991). O fósforo é o nutriente que possibilita respostas mais acentuadas na produção de feijão-vagem (Filgueira, 2008), enquanto o magnésio, como parte integrante da molécula da clorofila, é essencial para o crescimento das plantas e a base para realização da fotossíntese (Fontes, 2011).

Embora o K não tenha apresentado teor adequado na folha indicadora, observou-se aumento significativo do teor desse nutriente nas vagens, com o aumento das doses de esterco aplicadas. O máximo teor de $\mathrm{K}$ nas vagens foi estimado com a dose de 31,39 $\mathrm{tha}^{-1}$ de esterco de galinha (Figura 2A). O K favorece a formação e translocação das reservas na planta, constituídas por carboidratos, aumenta a eficiência do uso da água pela planta e auxilia no
$\mathbf{A}$

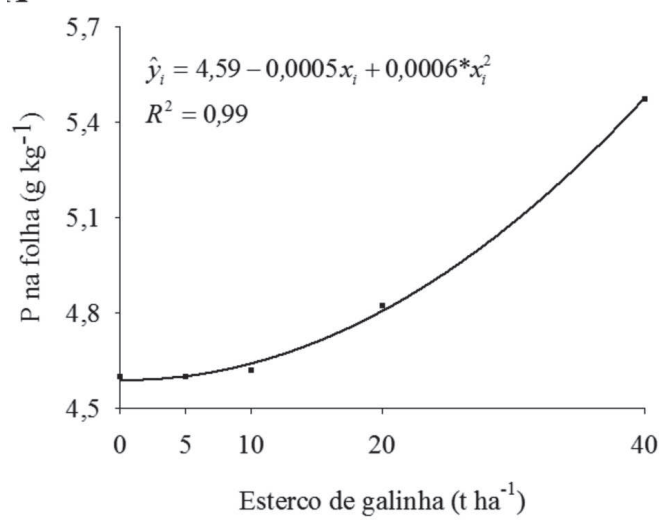

B



Figura 1: Teores de fósforo (A) e de magnésio (B) em folhas de feijão-vagem, cv. Macarrão favorito, adubadas com esterco de galinha. * significativo a $5 \%$ de probabilidade pelo teste $\mathrm{F}$, respectivamente. 
enchimento e no crescimento de grãos e frutos, melhorando a qualidade do produto e o valor de mercado (Filgueira, 2008). Oliveira et al. (2008) observaram o aumento do número de vagens por planta de feijão-vagem,em função de doses de $\mathrm{K}_{2} \mathrm{O}$, mostrando que o $\mathrm{K}$ desempenha importante papel na produção de vagens.

Observou-se também resposta significativa, de forma linear decrescente, dos teores de Ca nas vagens, em resposta ao aumento das dose de esterco de galinha (Figura 2B). Para o N, P, Mg e S, os teores médios nas vagens foram iguais a 33,$9 ; 4,2 ; 2,8$ e 2, $0 \mathrm{~g} \mathrm{~kg}^{-1}$, respectivamente. $\mathrm{O}$ aumento das doses de esterco proporcionou maior crescimento da parte aérea e reduziu a concentração de Ca nas vagens, provavelmente, por causa da baixa mobilidade do Ca nos tecidos, que depende da transpiração, sendo acumulado em tecidos que transpiram mais facilmente, principalmente nas folhas (Beninni et al., 2003). Além disso, o Ca é pouco móvel no floema, pois uma vez assimilado, não apresenta redistribuição para as outras partes da planta. Com isso, observou-se menor valor de Ca no fruto com o aumento das doses de esterco.

Não houve respostas significativas da massa da matéria fresca e da percentagem de matéria seca de vagens às doses de esterco de galinha, cujos valores médios foram 7,64 g e 8,99\%, respectivamente. Entretanto, houve respostas significativas do comprimento e do diâmetro da vagem e do número de vagens por planta (Figura 3). O máximo comprimento da vagem $(14,47 \mathrm{~cm})$ foi observado para a dose de 33,33 $\mathrm{t} \mathrm{ha}^{-1}$ de esterco de galinha (Figura 3A). A aplicação de esterco proporcionou o aumento linear do diâmetro da vagem, sendo o maior valor (10,29 mm) observado na maior dose (Figura 3B). Resultado semelhante ocorreu no número de vagens por planta, o qual foi maior com aplicação de $40 \mathrm{t} \mathrm{ha}^{-1}$ de esterco (Figura 3C). Esse aumento nos componentes da produção proporcionou resposta significativa da produtividade de vagens do cultivar Macarrão Favorito, tipo trepador.
Esse resultado pode ser associado ao maior estímulo ao desenvolvimento do sistema radicular, à formação dos primórdios reprodutivos e dos frutos, proporcionados pelo aumento da absorção de fósforo, em função das doses de esterco aplicadas (Ishimura et al., 1985). Araújo et al. (2001) trabalharam com o mesmo cultivar de feijãovagem e não encontraram resposta em diâmetro de vagens em função das doses de esterco suíno, na presença e na ausência da adubação mineral, com valores médios de 10,8 e 10,6 mm, muito próximos dos obtidos neste trabalho.

O maior número de vagens por planta (65) foi obtido com a maior dose de esterco (Figura 3C). Esse valor é maior do que o relatado por Oliveira et al. (2007), com o mesmo cultivar, na região de Areia, $\mathrm{PB}$, de 20 vagens por planta, com a adição de $145 \mathrm{~kg} \mathrm{ha}^{-1}$ de $\mathrm{K}_{2} \mathrm{O}$ em solo com 53,8 mg $\mathrm{dm}^{-3}$ de potássio residual. O maior número de vagens por planta, observado nesta pesquisa, provavelmente, foi ocasionado pelo equilíbrio entre os nutrientes, que, por sua vez, é mais importante para o ganho em produtividade do que o aumento das quantidades de macronutrientes, isoladamente. É provável também que as características físicas do solo tenham favorecido o melhor desenvolvimento das raízes das plantas e a absorção de nutrientes, pois a área experimental tem sido cultivada organicamente desde 2003 (Sediyama et al., 2014).

O número médio de vagens por planta foi o principal componente responsável pelo aumento da produtividade $(r \geq 0,99)$, visto que a massa média da vagem não apresentou respostas significativas, em função das doses de esterco. Resultados semelhantes foram obtidos por Ishimura et al. (1985), que observaram, ao utilizarem diferentes doses de NPK na produção de feijão-vagem, aumento significativo da produtividade e do número de vagem por planta, ausência de diferença entre as massas médias das plantas e enfatizaram o fósforo como o nutriente de grande importância na produção de frutos.
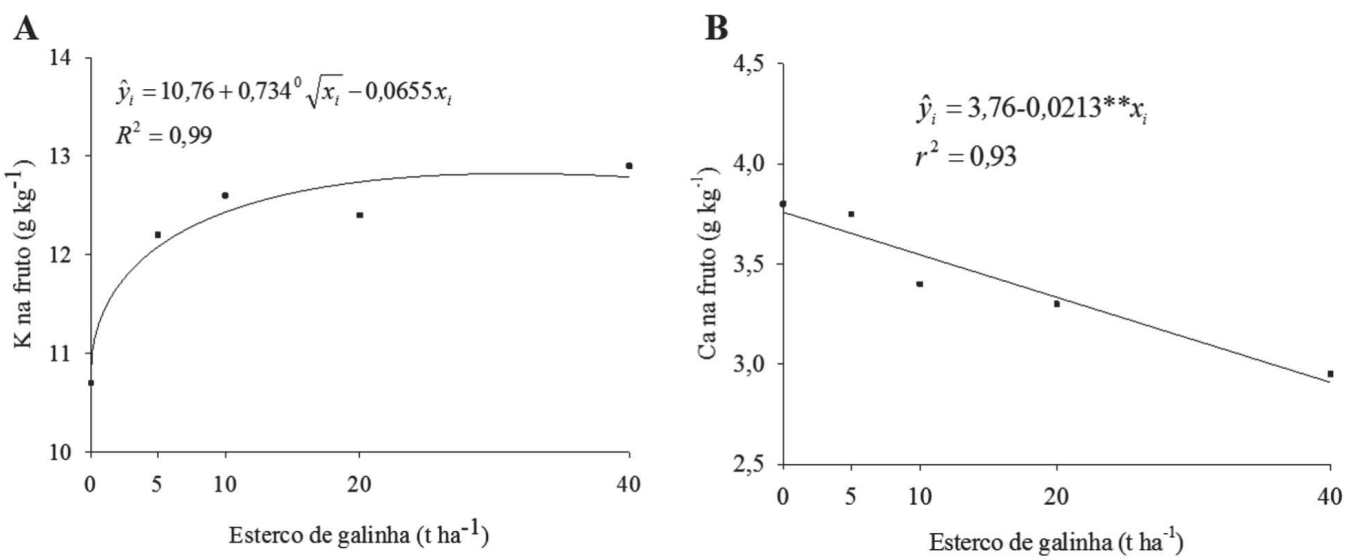

Figura 2: Teores de potássio (A) e de cálcio (B) em vagens de feijão-vagem, cv. Macarrão favorito, adubadas com esterco de galinha. $* *,{ }^{0}$, significativo a 5 e $10 \%$ de probabilidade pelo teste $\mathrm{F}$, respectivamente. 
A maior produtividade de vagens $\left(16,3 \mathrm{t} \mathrm{ha}^{-1}\right)$ foi alcançada com a dose de 40 tha $^{-1}$ de esterco (Figura 3D). É provável que a suplementação de nutrientes pelo esterco de galinha tenha favorecido o desenvolvimento das plantas nas fases vegetativa e reprodutiva. Santos et al. (2001) também constataram aumento de $11,3 \mathrm{t} \mathrm{ha}^{-1}$ da produtividade de vagens por meio da aplicação de esterco de galinha, obtendo-se produtividade máxima de $26,3 \mathrm{t} \mathrm{ha}^{-1} \mathrm{de}$ vagens, com 13,0 t ha-1 do esterco. De modo geral, as pro-

A

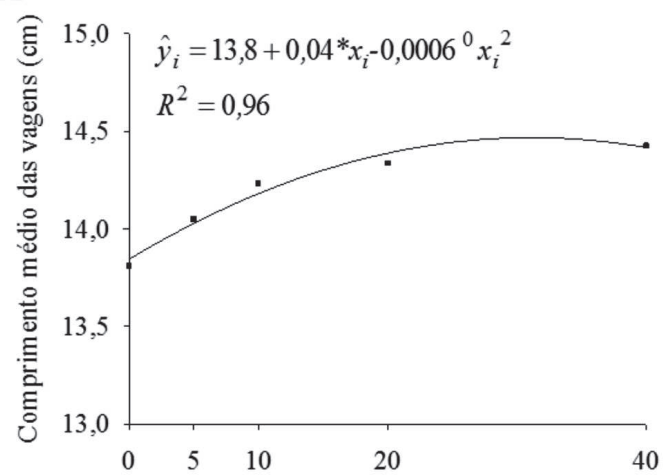

C



dutividades alcançadas nesta pesquisa são próximas das obtidas por Peixoto et al. (2002), que estudaram a adaptabilidade e a estabilidade de 15 genótipos de feijão-vagem, de crescimento indeterminado, em oito ambientes, e obtiveram valores entre 15,16 a 17,68 $\mathrm{t} \mathrm{ha}^{-1}$, com uma população de 50.000 plantas por ha.

As massas de matérias fresca e seca da parte aérea das plantas de feijão-vagem responderam de forma linear crescente ao aumento das doses de esterco de galinha. $\mathrm{Na}$


Figura 3: Comprimento médio das vagens (A), diâmetro médio das vagens (B), número médio das vagens (C), número médio das vagens por planta (D) e produtividade de vagens (E) das plantas de feijão-vagem, cv. Macarrão Favorito, cultivadas com esterco de galinha. *, ${ }^{0}$ significativo a 5 e $10 \%$ de probabilidade pelo teste $\mathrm{F}$, respectivamente.

A

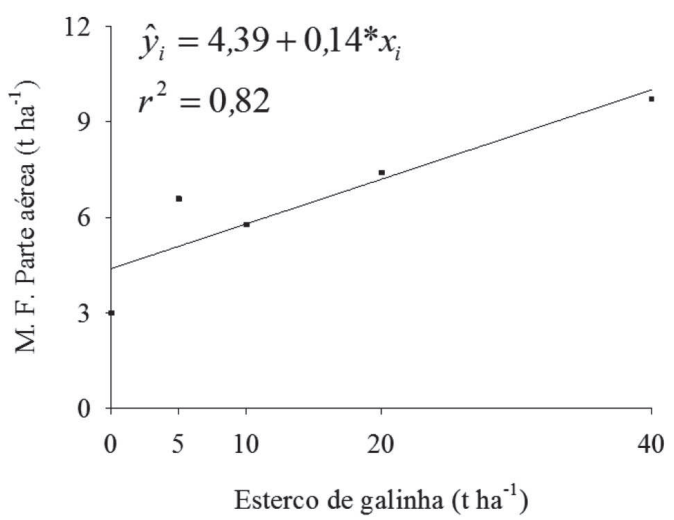

$\mathrm{B}$

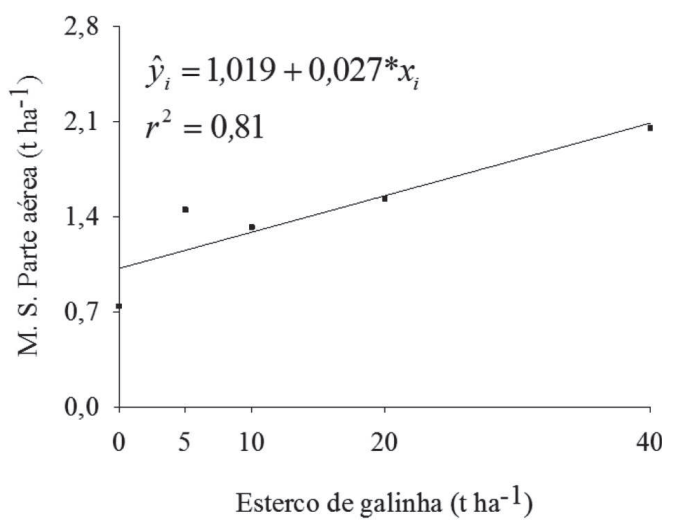

Figura 4: Matérias fresca (A) e seca (B) da parte aérea de plantas de feijão-vagem, cv. Macarrão favorito, adubadas com esterco de galinha. * significativo a $5 \%$ de probabilidade pelo teste $\mathrm{F}$. 
maior dose de esterco de galinha $\left(40 \mathrm{t} \mathrm{ha}^{-1}\right)$, foram obtidas 9,72 $\mathrm{t} \mathrm{ha}^{-1}$ de matéria fresca e 2,05 tha-1 de matéria seca, ou seja, aumentos de 6,72 t de matéria fresca e 1,31 t de matéria seca, ao comparar-se com as das plantas cultivadas sem adubação (Figuras 4A e 4B). As massas de matérias fresca e seca encontradas nos tecidos das plantas de feijão-vagem têm grande importância residual para o sistema de produção, pois retornam nutrientes e matéria orgânica, com a incorporação das plantas ao solo, e assim contribuem para o aumento e a manutenção da fertilidade do solo e, consequentemente, da produtividade .

A aplicação de esterco de galinha aumentou de forma linear os acúmulos de $\mathrm{K}$, Ca e $\mathrm{S}$ pelas plantas (massa de matéria fresca de plantas + vagens) (Figuras 5B, 5E e 5F).
Este comportamento pode ser atribuído também ao aumento da biomassa da planta, pois as doses crescentes de esterco não influenciaram os teores foliares desses nutrientes. Este resultado sugere que a concentração de nutrientes no solo estava em condições adequadas para suprir as necessidades das plantas.

Houve aumento linear para acúmulo de $\mathrm{N}, \mathrm{P}, \mathrm{Mg}$ e $\mathrm{S}$ pelas plantas (massa de matéria fresca de plantas + vagens), em função das doses de esterco aplicadas. No caso do N, o maior valor obtido foi de $101,1 \mathrm{~kg} \mathrm{ha}^{-1}$ de N (Figura $5 \mathrm{~A}$ ). A maior produtividade de vagens e o maior número de vagens por planta, além dos teores de nutrientes na planta, favoreceram o acúmulo de nutrientes. Neste trabalho, a maior produção de massa de matéria fresca da planta pode
A



C

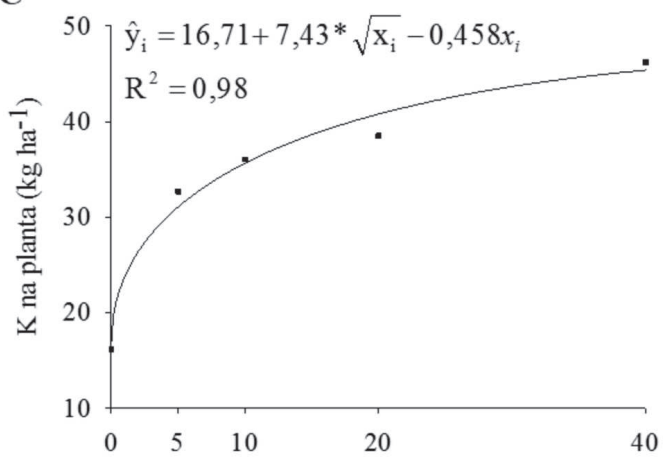

$\mathbf{E}$



B



D

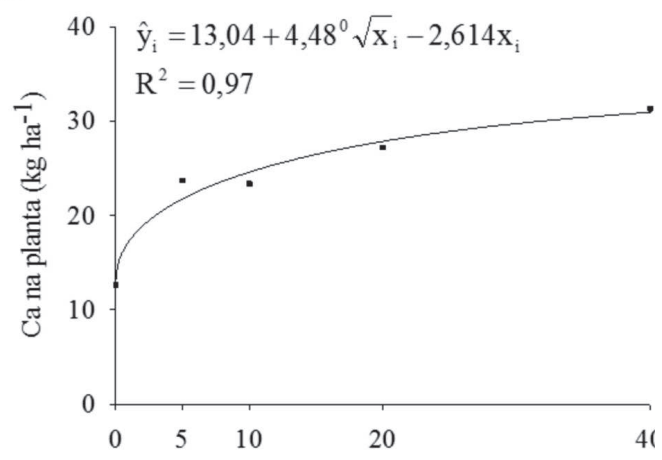

$\mathbf{F}$

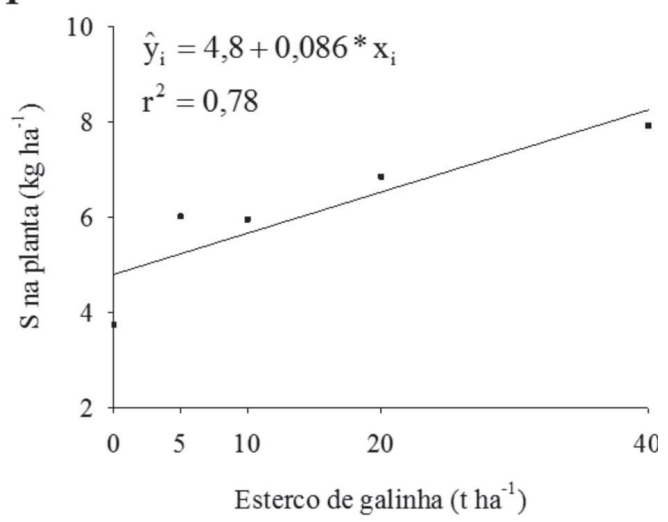

Figura 5: Acúmulos de nitrogênio (A), fósforo (B), potássio (K), cálcio $(\mathrm{Ca})$ magnésio $(\mathrm{Mg})$ e enxofre (S) pelas plantas de feijãovagem (plantas + vagens), cv. Macarrão favorito, adubadas com esterco de galinha. $* *, * \mathrm{e}^{0}$ significativo a 1,5 e $10 \%$ de probabilidade pelo teste $\mathrm{F}$, respectivamente.

Rev. Ceres, Viçosa, v. 64, n.1, p. 098-107, jan/fev, 2017 
ter sido o principal fator para maior acúmulo, pois o teor de $\mathrm{N}$ na folha não foi influenciado pelas doses crescentes de esterco de galinha.

O maior acúmulo de $\mathrm{P}\left(11,3 \mathrm{~kg} \mathrm{ha}^{-1}\right)$ ocorreu na maior dose de esterco aplicada. O acúmulo e a exportação de $\mathrm{P}$ são quantitativamente mais baixos que os dos outros macronutrientes, como $\mathrm{N}$ e $\mathrm{K}$, mas isso não implica que seu fornecimento seja menos importante. Pelo contrário, corresponde ao nutriente com maior resposta à adubação da cultura, pois à medida que aumentaram as doses de esterco de galinha, o acúmulo desse nutriente também aumentou (Figura 5B). É provável que o esterco de galinha, mesmo com teores de $\mathrm{P}$ relativamente baixos, em comparação com os teores das doses normalmente usadas na adubação mineral, proporcionou respostas signi- ficativas em seu teor nas folhas. Esse comportamento pode ser atribuído à competição pelos sítios de adsorção de P no solo, condição que ocasiona o aumento da disponibilidade desse nutriente para as plantas (Hue, 1991). Além disso, a área sob manejo orgânico apresenta melhor estrutura físico-química e melhor mobilidade de água, condições fundamentais para a absorção de P, que ocorre por difusão (Novais \& Smyth, 1999). Essa maior disponibilidade favoreceu maior teor de $\mathrm{P}$ nas folhas, consequentemente, maior acúmulo com o aumento da dose de esterco.

Com a maior produtividade $\left(16,3 \mathrm{tha}^{-1}\right)$, alcançada com a maior dose de esterco de galinha, as quantidades de macronutrientes exportadas pelas vagens, em ordem decrescente, foram, em kg ha-1, $\mathrm{N}(49,7)>\mathrm{K}(18,7)>\mathrm{P}(6,2)>$


D
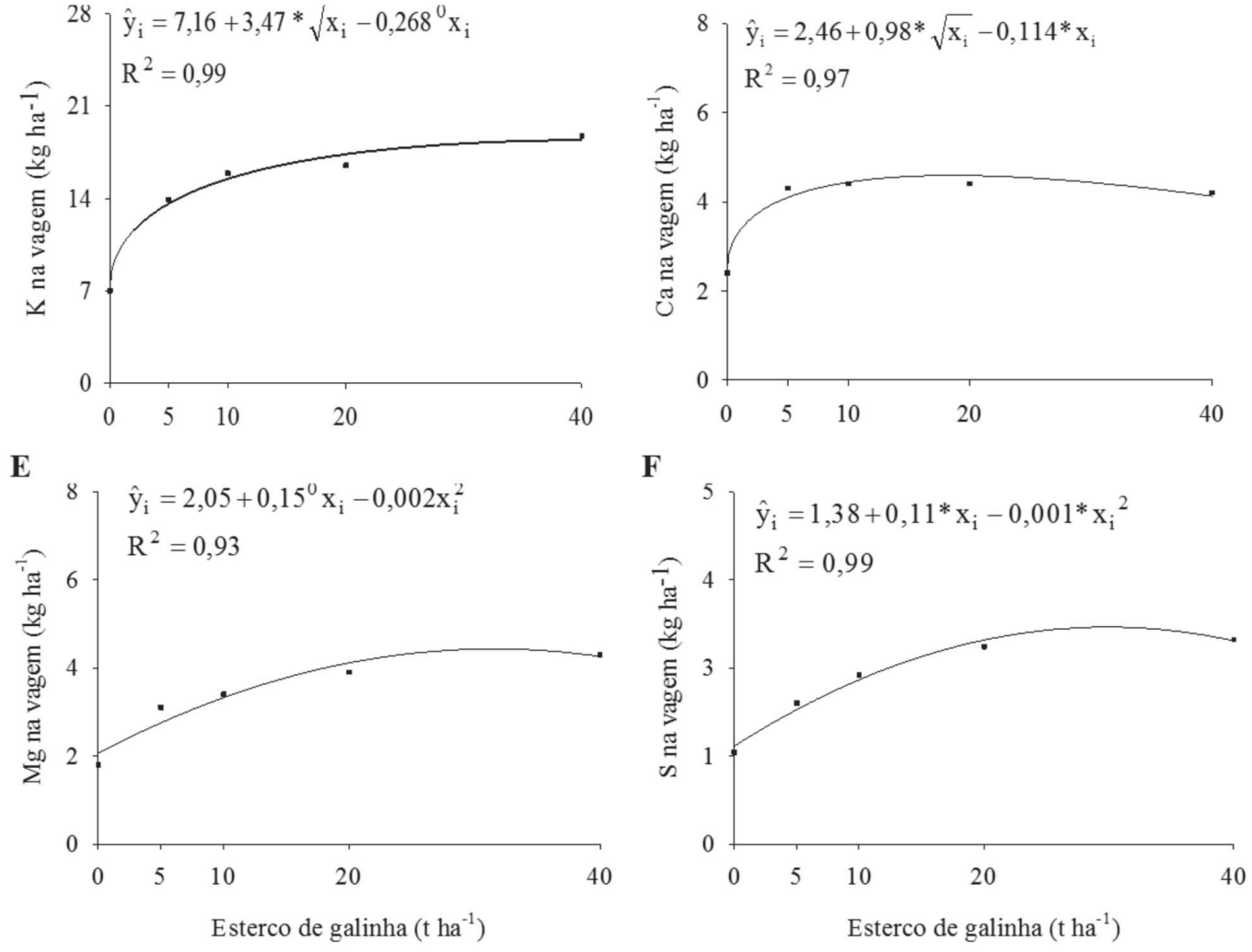

Figura 6: Exportação dos macronutrientes pelas vagens de feijão-vagem, cv. Macarrão favorito, adubadas com esterco de galinha. **, $*^{0}{ }^{0}$ significativo a 1,5 e $10 \%$ de probabilidade pelo teste $\mathrm{F}$, respectivamente. 
$\mathrm{Mg}(4,3)>\mathrm{Ca}(4,2)>\mathrm{S}(2,9)$. Assim, as quantidades exportadas pelas vagens apresentaram resposta significativa às doses aplicadas (Figura 6). Essas informações são fundamentais para auxiliar na indicação da melhor adubação da cultura, pois conhecendo a quantidade exportada pelas vagens é possível quantificar o que deve ser reposto ao solo antes de cada cultivo, em função da eficiência do fertilizante, para a manutenção da fertilidade e a garantia do potencial produtivo da cultura.

As doses de esterco não influenciaram nas proporções de nutrientes exportados, sendo estas iguais à média para todos os tratamentos. Em todas as doses, os nutrientes exportados em maior quantidade foram o $\mathrm{N} \mathrm{e}$ $\mathrm{K}$, com valores consideravelmente superiores aos dos demais nutrientes. No entanto, em termos relativos, ou seja, quantidade exportada em relação a total acumulado na parte aérea (massa de matéria fresca de plantas + vagens), o P é o nutriente mais exportado com a colheita das vagens, em média, $58 \%$, seguido de $\mathrm{N}(55 \%), \mathrm{K}(43 \%)$, $\mathrm{Mg}(40 \%), \mathrm{S}(35 \%)$ e Ca (17\%). Na maior dose, observouse que, embora o acúmulo de Ca na planta tenha sido de $31,3 \mathrm{~kg} \mathrm{ha}^{-1}$, apenas $13 \%$ deste foi exportado pelas vagens. Esse menor teor de Ca nas vagens pode ser explicado pela baixa mobilidade deste nutriente, com tendência a acumular na parte aérea e pouca translocação para os frutos.

A incorporação da parte aérea das plantas de feijãovagem adubadas com $40 \mathrm{tha}^{-1}$ de esterco de galinha poderá devolver ao solo as seguintes quantidades de macronutrientes $\left(\mathrm{kg} \mathrm{ha}^{-1}\right)$ : N (51,4); P (5,1); K $(27,6)$; Ca $(27,1) ; \operatorname{Mg}(8,2) ; \mathrm{S}(5,1)$. Assim, os restos vegetais do feijão-vagem constituem importante fonte de nutrientes, que podem retornar ao solo no final do ciclo da cultura e contribuir para a manutenção da sua fertilidade.

\section{CONCLUSÕES}

A adubação do solo com esterco de galinha para o cultivo de feijão-vagem cv. Macarrão Favorito melhora o estado nutricional da planta e aumenta a sua produtividade de 7,2 para 16,3 t ha-1, com aplicação de $40 \mathrm{t} \mathrm{ha}^{-1} \mathrm{de}$ esterco.

As quantidades de macronutrientes $\left(\mathrm{kg} \mathrm{ha}^{-1}\right)$ exportadas pelas vagens, em ordem decrescente, foram: $\mathrm{N}(49,7)>$ $\mathrm{K}(18,7)>\mathrm{P}(6,2)>\mathrm{Mg}(4,3)>\mathrm{Ca}(4,2)>\mathrm{S}(2,9)$, considerando-se uma produtividade de vagens de $16,3 \mathrm{tha}^{-1} \mathrm{e}$ adubação com $40 \mathrm{t} \mathrm{ha}^{-1}$ de esterco de galinha.

Os restos vegetais do feijão-vagem constituem importante fonte de nutrientes, sendo obtidas, na maior dose de esterco $\left(40 \mathrm{tha}^{-1}\right)$, as seguintes quantidades de macronutrientes $\left(\mathrm{kg} \mathrm{ha}^{-1}\right): \mathrm{N}(51,4) ; \mathrm{P}(5,1) ; \mathrm{K}(27,6) ; \mathrm{Ca}(27,1) ; \mathrm{Mg}$ $(8,2) ; \mathrm{S}(5,1)$, que poderão retornar ao solo, com a incorporação das plantas.

\section{AGRADECIMENTOS}

Os autores agradecem à Fundação de Amparo à Pesquisa do Estado de Minas Gerais (FAPEMIG) e ao Conselho Nacional de Desenvolvimento Científico e Tecnológico (CNPq), pelo auxílio financeiro ao projeto e pelas bolsas PIBIC, BIPDT e PQ.

\section{REFERÊNCIAS}

Abreu IMO, Junqueira AMR, Peixoto JR \& Oliveira AS (2010) Qualidade microbiológica e produtividade de alface sob adubação química e orgânica. Ciência e Tecnolologia de Alimentos, 30:108-118.

Araújo JS, Oliveira AP, Silva JAL, Ramalho CI \& Neto FLC (2001) Rendimento do feijão-vagem cultivado com esterco suíno e adubação mineral. Revista Ceres, 48:501-510.

Beninni ERY, Takahashi HW \& Neves CSVJ (2003) Manejo do cálcio em alface de cultivo hidropônico. Horticultura Brasileira, 21:605-610.

Brackmann A, Schorr MRW, Pinto JAV \& Venturini TL (2010) Aplicações pré-colheita de cálcio na qualidade pós-colheita de maçãs 'Fuji'. Ciência Rural, 40:1435-1438.

Brito MMP, Muraoka T \& Silva EC (2011) Contribuição da fixação biológica de nitrogênio, fertilizante nitrogenado e nitrogênio do solo no desenvolvimento de feijão e caupi. Bragantia, 70:206-215.

CEASAMINAS (2013) Centro de Abastecimento de Minas Gerais. Informações Nutricionais e Informações de Mercado. Disponível em: <http://www.ceasaminas.com.br> Acessado em: 5 de dezembro de 2014.

Cunha TJF, Blancaneaux P, Calderano Filho B, Carmo CAFS, Garcia NCP \& Lima BEM (2000) Influência da diferenciação pedológica no desenvolvimento da seringueira no município de Oratórios, MG. Pesquisa Agropecuária Brasileira, 35:145-155.

Embrapa - Empresa Brasileira de Pesquisa Agropecuária (2009) Manual de análises químicas de solos, plantas e fertilizantes. Brasília, Embrapa Informação Tecnológica. 627p.

Embrapa - Empresa Brasileira de Pesquisa Agropecuária (2013) Sistema Brasileiro de Classificação de Solos. $3^{a}$ ed. Brasília, Embrapa. 353p.

Filgueira FAR (2008) Novo Manual de Olericultura: Agrotecnologia moderna na produção e comercialização de hortaliça. Viçosa, UFV. 421p.

Fontes PCR (2011) Nutrição mineral de plantas: avaliação e diagnose. Viçosa, Arka. 296p.

Hue NV (1991) Effects of organic acids/anions on phosphorus sorption and phytoavailability in soils with different mineralogies. Soil Science, 152:463-471.

IBGE (2006) Censo Agropecuário Brasil. Grandes Regiões e Unidades da Federação. Disponível em: 〈www.ibge.gov.br〉. Acessado em: 23 de janeiro de 2015.

Ishimura I, Feitosa CT, Lisbão RS, Passos FA, Fornasier JB \& Noda M (1985) Diferentes doses de N, P, K na produção do feijão-vagem em solo orgânico álico do Vale do Ribeira (SP). Bragantia, 44:429-436.

Malavolta E, Vitti GC \& Oliveira AS (1997) Avaliação do estado nutricional das plantas: princípios e aplicações. $2^{\mathrm{a}}$ ed. Piracicaba, Potafos. 319p.

Miranda RS, Suderio FB, Sousa AF \& Gomes Filho E (2010) Deficiência nutricional em plântulas de feijão-de-corda decorrente da omissão de macro e micronutrientes. Revista Ciência Agronômica, 41:326-333. 
Novais RF \& Smyth TJ (1999) Fósforo em solo e planta em condições tropicais. Viçosa, UFV. 399p.

Oliveira AP, Cardoso MMO, Barbosa LJN, Silva JEL \& Morais MS (2005) Resposta do feijão-vagem a $\mathrm{P}_{2} \mathrm{O}_{5}$ em solo arenoso com baixo teor de fósforo. Horticultura Brasileira, 23:128-132.

Oliveira NG, De-Polli H, Almeida DL \& Guerra JGM (2006) Feijão-vagem semeado sobre cobertura viva perene de gramínea e leguminosa e em solo mobilizado, com adubação orgânica. Pesquisa Agropecuária Brasileira, 41:1361-1367.

Oliveira AP, Silva JA, Alves AU, Dorneles CSM, Alves AU, Oliveira ANP, Cardoso EA \& Silva Cruz IS (2007) Rendimento de feijão-vagem em função de doses de $\mathrm{K}_{2} \mathrm{O}$. Horticultura Brasileira, 25:29-33

Oliveira FL, Guerra JGM, Almeida DL, Ribeiro RLD, Silva ED, Silva VV \& Espindola JAA (2008) Desempenho de taro em função de doses de cama de aviário, sob sistema orgânico de produção. Horticultura Brasileira, 26:149-153.

Peixoto N, Braz LT, Banzatto DA \& Oliveira AP (2002) Adaptabilidade e estabilidade em feijão-vagem de crescimento indeterminado. Horticultura Brasileira, 20:616-618.

Perez AAG, Soratto RP, Manzatto NP \& Souza EFC (2013) Extração e exportação de nutrientes pelo feijoeiro adubado com nitrogênio, em diferentes tempos de implantação do sistema plantio direto. Revista Brasileira de Ciência do Solo, 37:12761287.
Raij B Van (1991) Fertilidade do solo e adubação. Piracicaba, Potafós. 343p.

Raij B Van, Cantarella H, Quaggio JA \& Furlani AMC (1997) Recomendações de adubação e calagem para o Estado de São Paulo. $2^{\mathrm{a}}$ ed. Campinas, IAC. 285p. (Boletim Técnico, 100).

Rosolem CA \& Marubayashi OM (1994) Seja o doutor do seu feijoeiro. In: Informações Agronômicas, 68:01-16.

SAEG (2007) SAEG: Sistema para análises estatísticas, versão 9.1. Viçosa, Fundação Arthur Bernardes. CD-ROM.

Santos GM, Oliveira AP, Silva JAL, Alves EU \& Costa CC (2001) Characteristics and yield of snap-bean pod in function of sources and levels of organic matter. Horticultura Brasileira, 19:30-35.

Santos DR, Gatiboni LC \& Kaminski J (2008) Fatores que afetam a disponibilidade do fósforo e o manejo da adubação fosfatada em solos sob sistema plantio direto. Ciência Rural, 38:576-586.

Sediyama MAN, Santos IC \& Lima PC (2014) Cultivo de hortaliças no sistema orgânico. Revista Ceres, 61:829-837.

Souza EFC, Soratto RP \& Pagani FA (2011) Aplicação de nitrogênio e inoculação com rizóbio em feijoeiro cultivado após milho consorciado com braquiária. Pesquisa Agropecuária Brasileira, 46:370-377.

UBA - União Brasileira de Avicultura (2014) Relatório Anual. Disponível em: 〈http://www.ubabef.com.br/publicacoes> Acessado em: 23 de janeiro de 2015. 